MEDICAL GAS

RESEARCH

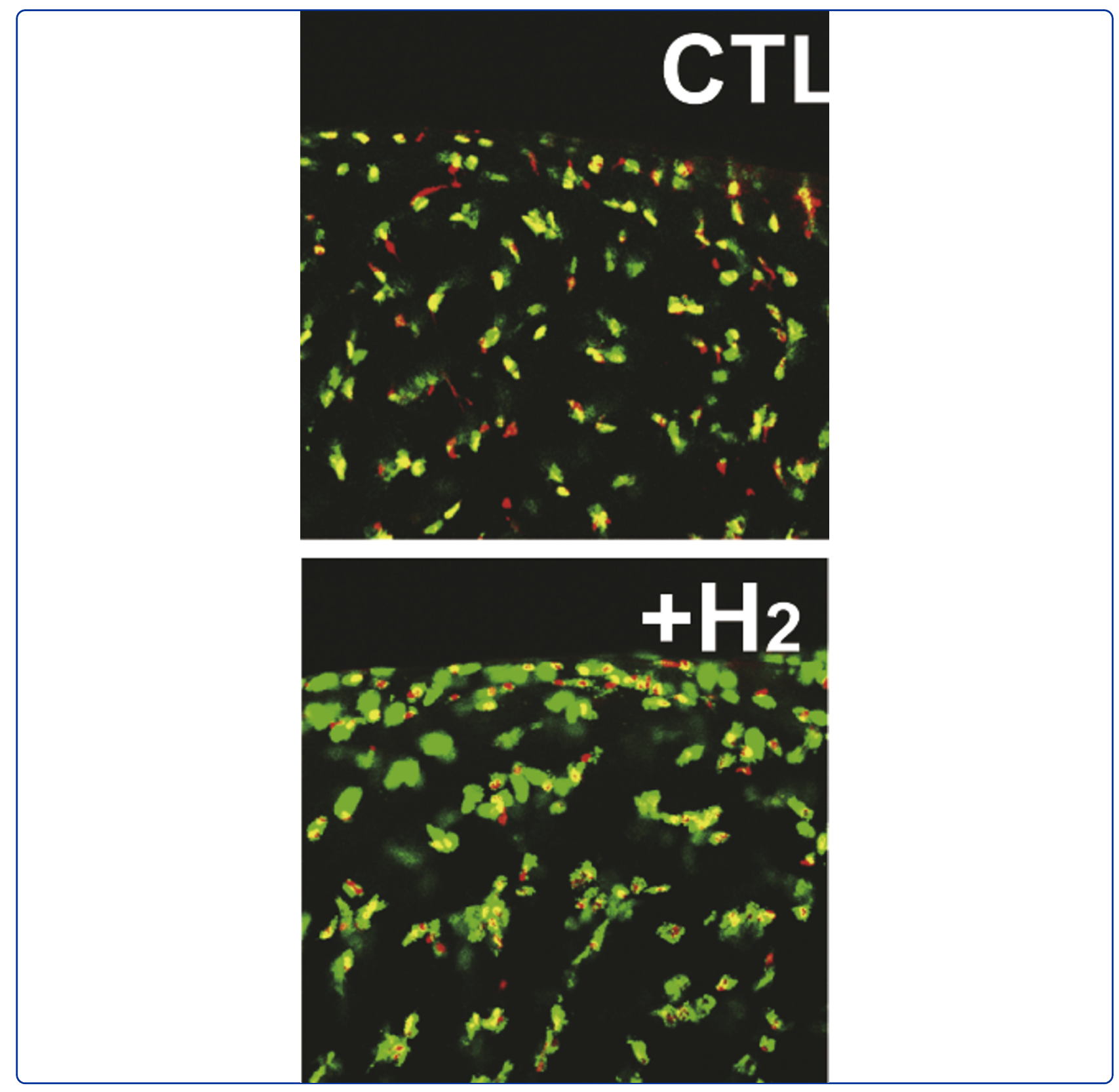

Molecular hydrogen protects chondrocytes from oxidative stress and indirectly alters gene expressions through reducing peroxynitrite derived from nitric oxide Hanaoka et al. 


\title{
Molecular hydrogen protects chondrocytes from oxidative stress and indirectly alters gene expressions through reducing peroxynitrite derived from nitric oxide
}

Teruyasu Hanaoka ${ }^{1,2}$, Naomi Kamimura', Takashi Yokota ${ }^{1}$, Shinro Takai ${ }^{2}$ and Shigeo Ohta ${ }^{2 *}$

\begin{abstract}
Background: Molecular hydrogen $\left(\mathrm{H}_{2}\right)$ functions as an extensive protector against oxidative stress, inflammation and allergic reaction in various biological models and clinical tests; however, its essential mechanisms remain unknown. $\mathrm{H}_{2}$ directly reacts with the strong reactive nitrogen species peroxynitrite (ONOO-) as well as hydroxyl radicals $(\cdot \mathrm{OH})$, but not with nitric oxide radical $(\mathrm{NO} \cdot)$. We hypothesized that one of the $\mathrm{H}_{2}$ functions is caused by reducing cellular $\mathrm{ONOO}^{-}$, which is generated by the rapid reaction of $\mathrm{NO} \cdot$ with superoxides $\left(\cdot \mathrm{O}_{2}{ }^{-}\right)$. To verify this hypothesis, we examined whether $\mathrm{H}_{2}$ could restore cytotoxicity and transcriptional alterations induced by $\mathrm{ONOO}^{-}$ derived from $\mathrm{NO} \cdot$ in chondrocytes.

Methods: We treated cultured chondrocytes from porcine hindlimb cartilage or from rat meniscus fibrecartilage with a donor of $\mathrm{NO}$, S-nitroso-N-acetylpenicillamine (SNAP) in the presence or absence of $\mathrm{H}_{2}$. Chondrocyte viability was determined using a LIVE/DEAD Viability/Cytotoxicity Kit. Gene expressions of the matrix proteins of cartilage and the matrix metalloproteinases were analyzed by reverse transcriptase-coupled real-time PCR method.

Results: SNAP treatment increased the levels of nitrated proteins. $\mathrm{H}_{2}$ decreased the levels of the nitrated proteins, and suppressed chondrocyte death. It is known that the matrix proteins of cartilage (including aggrecan and type II collagen) and matrix metalloproteinases (such as MMP3 and MMP13) are down- and up-regulated by ONOO, respectively. $\mathrm{H}_{2}$ restoratively increased the gene expressions of aggrecan and type II collagen in the presence of $\mathrm{H}_{2}$. Conversely, the gene expressions of MMP3 and MMP13 were restoratively down-regulated with $\mathrm{H}_{2}$. Thus, $\mathrm{H}_{2}$ acted to restore transcriptional alterations induced by ONOO'.
\end{abstract}

Conclusions: These results imply that one of the functions of $\mathrm{H}_{2}$ exhibits cytoprotective effects and transcriptional alterations through reducing $\mathrm{ONOO}^{-}$. Moreover, novel pharmacological strategies aimed at selective removal of $\mathrm{ONOO}^{-}$may represent a powerful method for preventive and therapeutic use of $\mathrm{H}_{2}$ for joint diseases.

\section{Background}

We have reported that molecular hydrogen $\left(\mathrm{H}_{2}\right)$ has potential as a novel antioxidant in preventive and therapeutic applications [1]. Furthermore, $\mathrm{H}_{2}$ exhibits not only anti-oxidative stress effects [2,3], but also has various anti-inflammatory $[4,5]$ and anti-allergic effects [6]. Since the publication of the first article on the biological

\footnotetext{
* Correspondence: ohta@nms.ac.jp

2Department of Orthopedic Surgery, Nippon Medical School, 1-1-5 Sendagi, Bunkyou-ku, Tokyo, 113-8602, Japan

Full list of author information is available at the end of the article
}

contribution of $\mathrm{H}_{2}$ in 2007, more than 80 articles involved in $\mathrm{H}_{2}$ have been published to establish the apparent activity of $\mathrm{H}_{2}$ from various medical aspects [7-9].

$\mathrm{H}_{2}$ reacted with strong reactive oxygen/nitrogen species including hydroxyl radical and peroxinitrite $\mathrm{ONOO}^{-}$ ) in cell-free reactions and protected cultured cells depending upon the decrease of hydroxyl radicals $(\bullet \mathrm{OH})$ [1]. Subsequent and recent experiments including ours indicated that a small amount of hydrogen is also effective against various stimuli $[8,9]$. When model animals

\section{Ciomed Central}


consumed $\mathrm{H}_{2}$ by drinking water with dissolved $\mathrm{H}_{2}$, a small amount of $\mathrm{H}_{2}$ was extensively effective [10-12]; however, it may be difficult to explain that direct reduction of $\cdot \mathrm{OH}$ by a very small amount of $\mathrm{H}_{2}$ reveals all the functions of $\mathrm{H}_{2}$, because the saturated level of $\mathrm{H}_{2}$ is only $0.8 \mathrm{mM}$ and the dwelling time of $\bullet \mathrm{OH}$ is very short in the body [11,13]. In fact, drinking 0.04 or $0.08 \mathrm{mM} \mathrm{H}_{2}$ was shown to be effective [14,15]. Although we have recently shown that $\mathrm{H}_{2}$ can be accumulated with hepatic glycogen, it is unlikely that the amount of $\mathrm{H}_{2}$ is sufficient to exhibit all of its functions [15].

Moreover, $\mathrm{H}_{2}$ regulated various gene expressions; however, there is no evidence that $\mathrm{H}_{2}$ directly reacts with factors involved in transcriptional regulation including FGF21 [15], inflammatory cytokines [11], HMGB1 [16], and HO-1 [17]. It remains unclear whether such regulations are the cause or consequence of the effects against oxidative stress. Moreover, the primary molecular target of $\mathrm{H}_{2}$ remains unknown.

$\mathrm{ONOO}^{-}$is produced by the rapid reaction of nitric monoxide (NO $\bullet$ ) with superoxide anion radicals $\left(\bullet \mathrm{O}_{2}{ }^{-}\right)$ $[18,19]$. We have shown that $\mathrm{H}_{2}$ reduces $\mathrm{ONOO}^{-}$as well as $\bullet \mathrm{OH}[1]$. Different from $\bullet \mathrm{OH}, \mathrm{ONOO}^{-}$has a longer lifespan and the potential to regulate gene expression through nitration of target proteins $[20,21]$. Thus, we hypothesized that one of the $\mathrm{H}_{2}$ functions is caused by reducing cellular $\mathrm{ONOO}^{-}$.

Here, to verify this hypothesis, we examined protective and regulatory effects of $\mathrm{H}_{2}$ on $\mathrm{NO}$-derived oxidative stress to chondrocytes. We found that $\mathrm{H}_{2}$ protected chondrocytes from oxidative stress, and alternated gene expressions, contrary to the manner of transcriptional regulation by $\mathrm{ONOO}^{-}$. This study implies that at least one of the $\mathrm{H}_{2}$ functions is responsible for the reduction of $\mathrm{ONOO}^{-}$.

\section{Methods}

\section{Cartilage slice culture}

A fresh hindlimb of a slaughtered male seven-month-old pig was purchased from Tokyo Shibaura Organ Co., Ltd. (Minato-ku, Tokyo, Japan). There were no possible contaminant diseases. Cartilage from the healthy porcine hindlimb (metatarsophalangeal joint) was cut into pieces for culture $(2 \mathrm{~mm}$ width $\times 7 \mathrm{~mm}$ length $\times$ full thickness) as described previously [22]. Male Sprague-Dawley rats of 10 weeks of age were purchased from Nippon SLC (Hamamatsu, Shizuoka, Japan). Cartilage from the meniscus of a rat was also sliced into pieces (full width $\times$ full length $\times 0.5 \mathrm{~mm}$ thickness) for culture. Since the meniscus structure is not uniform and the peripheral part contains fewer chondrocytes, we used slices prepared from the middle part of the meniscus.

The slices were randomly divided into two experimental groups and incubated at $37^{\circ} \mathrm{C}$ in Dulbecco's modified
Eagle's medium (DMEM)/Ham F-12 mixed medium (Gibco Invitrogen, Grand Island, NY, USA) supplemented with $10 \%$ fetal calf serum (FBS), penicillin (100 U/ $\mathrm{ml})$, and streptomycin $(100 \mu \mathrm{g} / \mathrm{ml})$.

The care and use of laboratory animals were in accordance with the NIH guidelines. This study was approved by the Animal Care and Use Committee of Nippon Medical School (Bunkyo-ku, Tokyo, Japan).

\section{Hydrogen treatment}

We prepared $\mathrm{H}_{2}$-dissolved culture medium as described previously [1]. In brief, we dissolved $\mathrm{H}_{2}$ in the medium by bubbling $\mathrm{H}_{2}$ gas to the saturated level. We also dissolved $\mathrm{O}_{2}$ in a second medium by bubbling $\mathrm{O}_{2}$ gas, and $\mathrm{CO}_{2}$ in a third medium by bubbling $\mathrm{CO}_{2}$ gas. We combined these media to give a medium consisting of $75 \%$ $\mathrm{H}_{2}, 20 \% \mathrm{O}_{2}, 5 \% \mathrm{CO}_{2}(\mathrm{vol} / \mathrm{vol} / \mathrm{vol})$. We then cultured the cartilage slices in a closed culture flask filled with the medium. Control medium contained $75 \% \mathrm{~N}_{2}$ instead of $\mathrm{H}_{2}$. The $\mathrm{H}_{2}$ concentration was maintained for $24 \mathrm{hr}$ as described [15].

\section{Cell death assay}

The cartilage slices were incubated for $12-80 \mathrm{hr}$ in medium containing $0.3-3 \mathrm{mM} S$-nitroso- $N$-acetyl-D, Lpenicillamine (SNAP) (Cayman Chemical, Ann Arbor, MI, USA) in the presence or absence of $\mathrm{H}_{2}[22,23]$. Chondrocyte viability was determined using a LIVE/ DEAD Viability/Cytotoxicity Kit (Molecular Probes, Eugene, OR, USA). Living, dying and dead cells were stained with green, yellow (combination of green and red) and red fluorescence, respectively, and visualized with a confocal scanning laser microscope (FLUOVIEW FV300; Olympus, Tokyo, Japan).

\section{Immunohistochemical staining}

Frozen sections of $6 \mu \mathrm{m}$-thick were fixed with $10 \%$ formalin and treated with $0.3 \%$ hydrogen peroxide in methanol to inhibit endogenous peroxidase activity. The sections were incubated with $10 \%$ Block Ace (DS Pharma Biomedical Co., Ltd., Suita, Osaka, Japan) in phosphate buffered saline (PBS) and then incubated with anti-nitrotyrosine monoclonal antibody (Calbiochem, San Diego, CA, USA; 1:100 dilution with 10\% Block Ace in PBS) overnight at $4{ }^{\circ} \mathrm{C}$. Nitrotyrosine residues were visualized with $\mathrm{DAB}$ using horseradish peroxidase (HRP)-conjugated secondary antibody (Santa Cruz Biotechnology, Inc. Santa Cruz, CA, USA) and a HistoMark ORANGE kit (KPL, Gaithersburg, MD, USA). As a positive control for staining, we used sections from cartilage treated with $1 \mathrm{mM} 3$-morpholinosydnonimine (SIN-1) (Sigma-Aldrich, St. Louis, MO, USA), which generates both superoxide anion and nitric oxide that spontaneously produce peroxynitrite. The positive area 
was estimated using the Image J program (version 1.41; National Institutes of Health, Bethesda, MD, USA) from four sections for each group.

\section{RNA isolation and RT-PCR}

Total RNA was isolated from the cartilage using an RNeasy Mini kit (QIAGEN, Valencia, CA, USA). Complementary DNA synthesized by SuperScript II Reverse Transcriptase (Invitrogen, Carlsbad, CA, USA) was analyzed by quantitative PCR using the Thermal Cycler Dice Real Time System TP800 (TAKARA BIO Inc., Otsu, Shiga, Japan). All samples were normalized to glyceraldehyde 3-phosphate dehydrogenase (GAPDH) expression. Primer and probe sequences for each PCR are listed in Table 1.

\section{Immunoblot analysis}

Specimens were homogenized with a micro-homogenizer in SDS (sodium dodecyl sulfate) buffer (1\% SDS in $\mathrm{PBS}$ ), and then centrifuged at $10,000 \mathrm{~g}$ for $10 \mathrm{~min}$ at $4^{\circ}$ $\mathrm{C}$ to remove debris. Supernatants were subjected to SDS-PAGE (SDS-polyacrylamide gel electrophoresis) followed by electrotransfer onto a PVDF membrane. The blotted membranes were blocked with Block Ace (DS Pharma Biomedical Co., Ltd.) and incubated with antiaggrecan polyclonal antibody (Abcam, Cambridge, UK; 1:1,000 dilution), anti-MMP13 polyclonal antibody (Santa Cruz Biotechnology, Inc. 1:1,000 dilution) or anti-actin monoclonal antibody (Sigma-Aldrich; 1:500 dilution) overnight at $4{ }^{\circ} \mathrm{C}$. Each band was visualized with horseradish peroxidase (HRP)-conjugated secondary antibody (Santa Cruz Biotechnology, Inc.) and an ECL plus Western blotting detection system (GE Healthcare, Piscataway, NJ, USA).

Table 1 Primers and probes for RT-PCR.

\begin{tabular}{|c|c|c|}
\hline Gene & & Sequence \\
\hline \multirow[t]{3}{*}{ aggrecan } & F primer & 5'-GACCAGGAGCAATGTGAGGAG-3' \\
\hline & R primer & 5'-CTCGCGGTCGGGAAAGT-3' \\
\hline & probe & 5'-CCAAGTTCCAGGGCCACTGTTATCGC-3' \\
\hline \multirow[t]{3}{*}{ type II collagen } & F primer & 5'-TTGGAGAGACCATGAACGGC-3' \\
\hline & R primer & 5'-TTAGCGGTGTTGGGAGCC-3' \\
\hline & probe & 5'-CACTTCAGCTACGGCGACGGCAA-3' \\
\hline \multirow[t]{3}{*}{ MMP3 } & F primer & 5'-TCCCAGGAAAATAGCTGAGAACTT-3' \\
\hline & R primer & 5'-AAACCCAAATGCTTCAAAGACAG-3' \\
\hline & probe & 5'-CCAGGCATTGGCACAAAGGTGGA-3' \\
\hline \multirow[t]{3}{*}{ MMP13 } & F primer & 5'-TGGAGTTATGATGATGCTAACCAGAC-3' \\
\hline & R primer & 5'-TGTCGCCAATTCCAGGGA-3' \\
\hline & probe & $\begin{array}{l}\text { 5'-TGGACAAAGACTATCCCCGCCTCATA } \\
\text { GAAG-3' }\end{array}$ \\
\hline \multirow[t]{3}{*}{ GAPDH } & F primer & 5'-CATCACTGCCACCCAGAAGA-3' \\
\hline & R primer & 5'-ATGTTCTGGGCAGCC-3' \\
\hline & probe & 5'-TGGATGGCCCCTCTGGAAAGCTG-3' \\
\hline
\end{tabular}

\section{Statistical analysis}

We performed statistical analysis using StatView software (SAS Institute) by applying an unpaired two-tailed Student's t-test and ANOVA followed by Fisher's exact test, as described previously [1]. Differences were considered significant at $\mathrm{p}<0.05$.

\section{Results}

\section{$\mathrm{H}_{2}$ protects chondrocytes of hyaline and fibrecartilage} from cell death

It is reported that cultured chondrocytes are sensitive to exposure to SNAP, a donor of $\mathrm{NO} \cdot[22]$ and that $\mathrm{H}_{2}$ exhibits no direct reaction with $\mathrm{NO}$ - in cultured cells as well as in a cell-free reaction. To verify the hypothesis that $\mathrm{H}_{2}$ protects cells by reducing $\mathrm{ONOO}^{-}$, we examined the effect of $\mathrm{H}_{2}$ on cell death induced by SNAP by using hyaline cartilage slices from a porcine hindlimb metatarsophalangeal joint as a target. Chondrocyte viability was determined using a LIVE/DEAD Viability/Cytotoxicity Kit, which provides quantitative analyses of the proportion of live and dead cells in a mixed population (Figure 1A). In living cells, membrane-permeated calcein AM is cleaved by esterases to yield cytoplasmic green fluorescence, and in dead cells membrane-impermeable ethidium homodimer1 labels nucleic acids with red fluorescence. Dying cells, whose membrane structure has been disrupted but still have some esterase activity, were double stained as yellow. We counted green, red and yellow cells for statistical analysis (Additional file 1: Table S1). Cell viability was calculated as the percentage of green cell numbers against total cell numbers (Figure 1B). Significant protection of chondrocytes by $\mathrm{H}_{2}$ was observed in the treatment with $3 \mathrm{mM}$ SNAP for $12 \mathrm{hr}$ (Figure 1A and 1B). More evident effects were obtained with longer SNAP treatment (Figure 1B).

Next, we examined another type of cartilage, meniscus fibrecartilage, isolated from rats instead of swine specimens. Because it is easier to isolate swine than rat cartilage, we used swine cartilage for preliminary experiments; however, for further analysis, cartilage from rats is more suitable for RNA and protein analysis because genomic databases and antibodies are available. Treatment with 1 mM SNAP induced cell death in a time-dependent manner and $\mathrm{H}_{2}$ suppressed chondrocyte death at each time point (Figure 2A and 2B, Additional file 2: Table S2). $\mathrm{H}_{2}$ significantly protected chondrocytes from death with various concentrations of SNAP treatment for $48 \mathrm{hr}$ (Figure 2C, Additional file 3: Table S3). These results indicate that $\mathrm{H}_{2}$ protects chondrocytes by stimuli derived from NO. although $\mathrm{H}_{2}$ has no potential to react with NO.

\section{$\mathrm{H}_{2}$ decreases nitrotyrosine in chondrocytes and matrix of cartilage induced by SNAP}

$\mathrm{ONOO}^{-}$is a strong modifier of nitration in proteins. To confirm that $\mathrm{H}_{2}$ decreased $\mathrm{ONOO}^{-}$derived from $\mathrm{NO}$, 

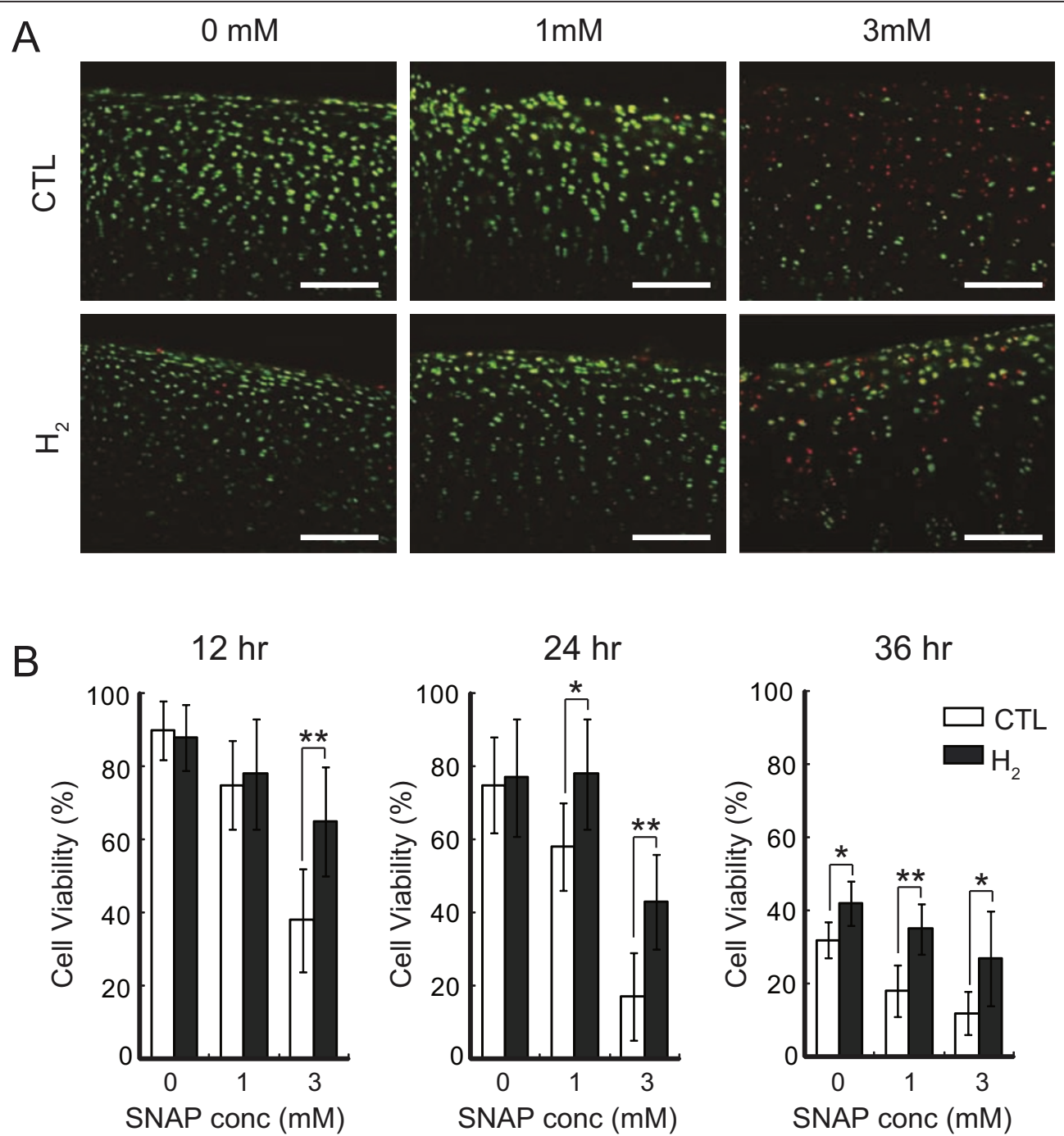

Figure 1 Hydrogen protects chondrocytes of hyaline cartilage from cell death. (A) Porcine cartilage slices were incubated with 0,1 or 3 mM SNAP in the presence or absence of hydrogen for $12 \mathrm{hr}$ at $37^{\circ} \mathrm{C}$. Cells were stained with a mixture of calcein AM (Live cell: green) and ethidium homodimer (Dead cell: red) as described in Materials and methods. Scale bar: $100 \mu \mathrm{m}$. (B) Chondrocyte viability was determined by counting green and red cells from three areas of each slice. Six slices were used for each experimental group. The slices were incubated with 0 , 1 or $3 \mathrm{mM} \mathrm{SNAP}$ in the presence or absence of hydrogen for 12,24 or $36 \mathrm{hr}$ at $37^{\circ} \mathrm{C}$. Data are the means $\pm \mathrm{SD}(n=6)$. ${ }^{*} p<0.05 ;{ }^{* *} p<0.01$.

we examined levels of nitrotyrosine residues in cartilage immunohistologically. In fact, NO increased the levels of nitrotyrosine, and $\mathrm{H}_{2}$ restored its increase (Figure 3). Thus, $\mathrm{H}_{2}$ should decrease $\mathrm{ONOO}^{-}$derived from $\mathrm{NO}$.

$\mathrm{H}_{2}$ restores down-regulation of matrix expression and upregulation of matrix-metallo protease expression induced by SNAP

It was also reported that $\mathrm{ONOO}^{-}$down-regulates gene expressions of the cartilage matrix proteins including aggrecan and type II collagen [24]. Conversely, levels of matrix-metallo protease are known to be up-regulated by $\mathrm{ONOO}^{-}$[24]. We then investigated the effect of $\mathrm{H}_{2}$ on the expression of chondrocyte-specific matrix genes.
Isolated meniscus fibrecartilage was incubated in DMEM/F-12 supplemented with $10 \%$ FBS with or without $1 \mathrm{mM}$ SNAP in the presence or absence of $\mathrm{H}_{2}$. The levels of mRNA for the matrix proteins of type II collagen and aggrecan core protein were quantified with real-time PCR coupled with reverse transcription (Figure $4 \mathrm{~A}$ and $4 \mathrm{~B}$ ). Indeed, SNAP down-regulated aggrecan and collagen II gene expressions as expected. The decreased gene expressions of the matrix proteins were significantly restored by $\mathrm{H}_{2}$-dissolved culture medium, suggesting that the decreased $\mathrm{ONOO}^{-}$restored the gene expression.

The possibility cannot be ruled out that oxidative damage derived from SNAP may reduce any gene expressions in a non-specific manner. We examined therefore 

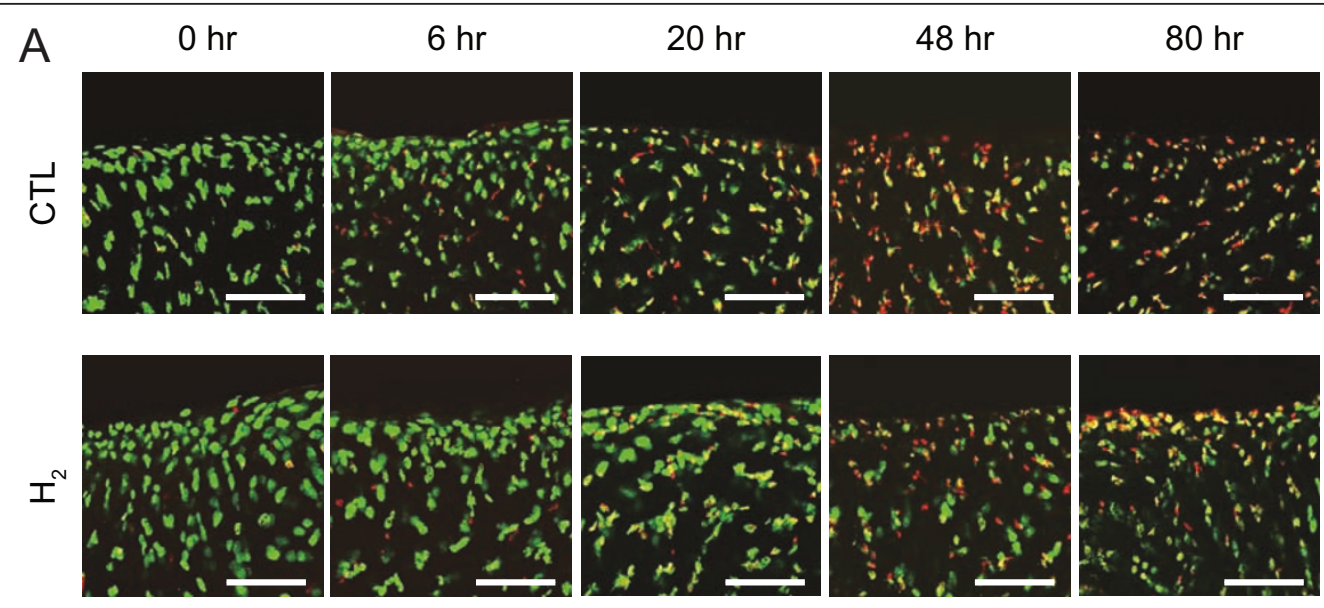

B

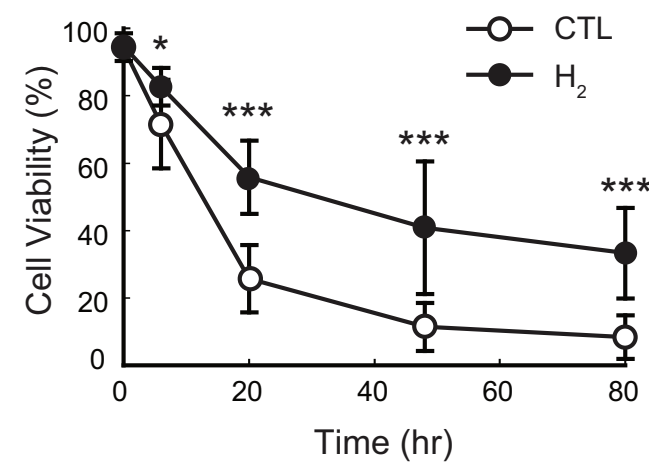

C

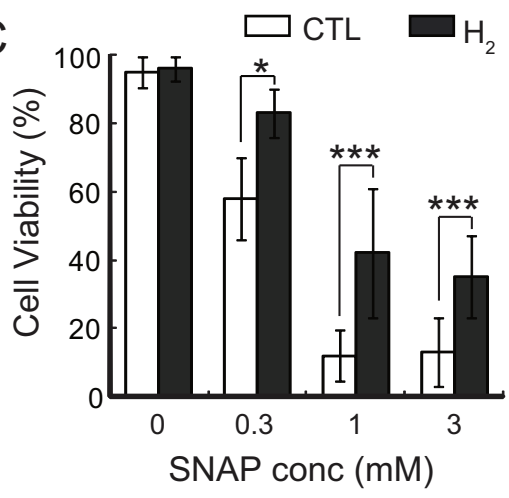

Figure 2 Hydrogen protects chondrocytes of fibrocartilages from cell death. (A) Meniscus fibrocartilages from SD rats was incubated with 1 mM SNAP in the presence or absence of hydrogen for $0,6,20,48$, or $80 \mathrm{hr}$ at $37^{\circ} \mathrm{C}$. Cells were stained with calcein AM (Live cell: green) and ethidium homodimer (Dead cell: red) as described in Materials and methods. Scale bar: 40 mm. (B) Chondrocyte viability was determined by counting green and red cells from three regions of each slice. Six slices were used for each experimental group. The slices were incubated with $1 \mathrm{mM}$ SNAP in the presence or absence of hydrogen for the indicated periods at $37^{\circ} \mathrm{C}$. Data are the means $\pm \mathrm{SD}(n=6) .{ }^{*} p<0.05 ;{ }^{* *} p<0.001$. (C) The slices were incubated with $0,0.3,1$, or $3 \mathrm{mM} \mathrm{SNAP}$ in the presence or absence of hydrogen for $48 \mathrm{hr}$ at $37^{\circ} \mathrm{C}$. Data are the means \pm SD $(n=6) .{ }^{*} p<0.05 ;{ }^{* * *} p<0.001$.

the effect of $\mathrm{H}_{2}$ on catabolic enzyme genes induced by SNAP, because levels of matrix-metallo protease are known to be contradictorily up-regulated by $\mathrm{ONOO}^{-}$[24]. The levels of MMP-3 and MMP-13 mRNA were measured with quantitative real-time PCR after treatment with SNAP with or without $\mathrm{H}_{2}$ (Figure 4D and 4E). Moreover, the alterations of the aggrecan and MMP-13 proteins corresponded to their mRNA levels (Figure 4F). Thus, SNAP up-regulated MMP-3 and MMP-13 gene expressions as expected, whereas $\mathrm{H}_{2}$ significantly suppressed MMP gene expressions, suggesting that $\mathrm{H}_{2}$ restored the increased expressions by decreasing $\mathrm{ONOO}^{-}$.

\section{Discussion}

Joint diseases including osteoarthritis (OA) and rheumatoid arthritis (RA) are the most common disabling diseases, especially among elderly people. Arthritis is a degenerative disease involving abnormalities in chondrocytes, articular cartilage and other joint tissue, and is mediated by a number of underlying biochemical and physical stimuli $[25,26]$. Recent studies revealed that oxidative stress plays a leading role in the initiation and progression of the disease process $[27,28]$. As a joint disease model of aged patients, we stimulated chondrocytes with oxidative stress derived from NO. The cartilage consists mostly of the extracellular matrix, which is synthesized by chondrocytes [28,29]. The extracellular matrix is composed of collagens and proteoglycans that are responsible for the important compressive and tensile properties of cartilage [28].

The major oxidative stress generated by chondrocytes is one of the most powerful oxidants $\mathrm{ONOO}^{-}$, which was produced by the rapid reaction of $\mathrm{NO} \cdot$ with $\cdot \mathrm{O}_{2}{ }^{-}$ $[18,19]$. At an earlier stage, NO has been considered as the primary inducer of chondrocyte death [30]; however, it has been revealed that the oxidative strength of NO. 

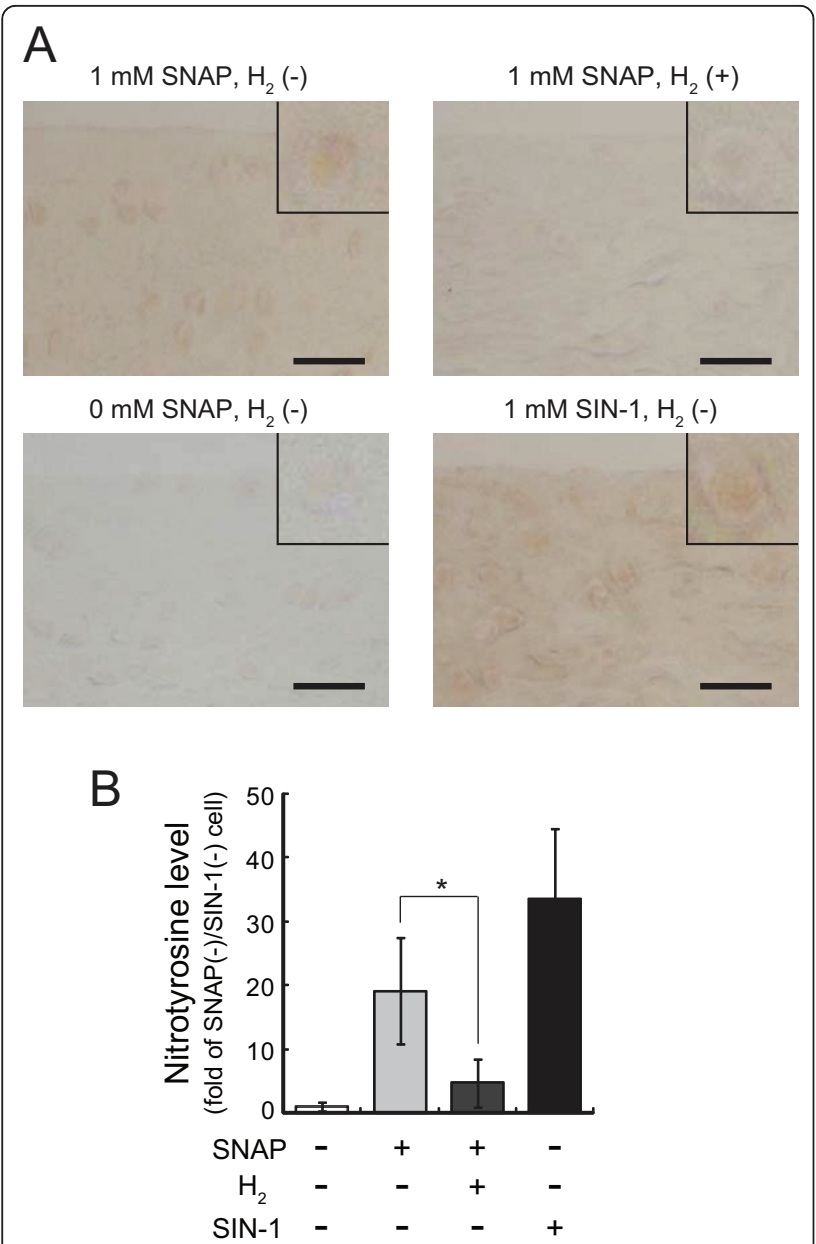

Figure 3 Hydrogen decreases nitrotyrosine in chondrocytes and cartilage matrix. (A) Meniscus fibrocartilage from SD rats was incubated with $1 \mathrm{mM}$ SNAP in the presence or absence of hydrogen for $3 \mathrm{hr}$ at $37^{\circ} \mathrm{C}$. Frozen sections were stained with antinitorotyrosine antibody and visualized with DAB as described in Methods. The inset shows chondrocytes. Cartilage incubated with 1 mM SIN-1 and without SNAP was used for positive and negative staining controls, respectively. Scale bar: $40 \mu \mathrm{m}$. (B) Levels of nitrotyrosine in cartilage were estimated from anti-nitrotyrosine immunostaining using an image analysis program, Image J program. Data are the mean $\pm S D(n=4)$. ${ }^{*} p<0.05$; control versus hydrogen in $1 \mathrm{mM}$ SNAP-treated groups.

is not sufficient to initiate cell death [31,32]. A series of experiments have indicated that the major cytotoxicity attributed to NO, is rather due to $\mathrm{ONOO}^{-}[20,33]$. Increased $\mathrm{ONOO}^{-}$formation has been observed in cartilage and subchondral bone in rodent models [34-36] and in cartilage in OA and RA patients [37-39]. ONOO- induces cell death and regulates the decreased expression of collagens and proteoglycans and increased matrix metallo proteinases in chondrocytes, resulting in matrix degradation $[24,40]$. Thus, chondrocyte is a suitable target for investing the effect of $\mathrm{H}_{2}$ regarding $\mathrm{ONOO}^{-}$in this study.
In this study, we show that $\mathrm{H}_{2}$ protected chondrocytes from death induced by SNAP. SNAP is a donor of NO; however, $\mathrm{NO}$. has no strong toxicity itself and $\mathrm{H}_{2}$ has no potential to reduce NO. Our previous study demonstrated that $\mathrm{H}_{2}$ reduces $\mathrm{ONOO}^{-}$in a cell-free system [1]. Thus, we speculate that $\mathrm{H}_{2}$ would protect SNAPtreated chondrocytes by decreasing $\mathrm{ONOO}^{-}$. More importantly, it has been reported that drinking hydrogen water suppress the nitration of kidney proteins, although $\mathrm{H}_{2}$ received from hydrogen water remained for only short period in the organ (less than $5 \mathrm{~min}$ ) [11]. In this study, we have shown that $\mathrm{H}_{2}$ in medium suppress the nitration of the chondrocyte proteins (Figure 3). Thus, it is possible that even a very small amount of $\mathrm{H}_{2}$ exhibits anti-oxidative effects by reducing $\mathrm{ONOO}^{-}$in many situations.

Several laboratories including ours have reported that $\mathrm{H}_{2}$ altered gene expressions involved in inflammation or energy metabolism when animals drank hydrogen water [15,17]; however, it is an open question why $\mathrm{H}_{2}$ alters gene expressions, because there is no evidence that $\mathrm{H}_{2}$ directly influences gene expressions. On the other hand, $\mathrm{ONOO}^{-}$has the potential to regulate gene expressions through the nitration of factors involved in transcriptional regulation [20]. As mentioned above, drinking hydrogen water suppresses the nitration of proteins; thus, it is possible that the very small amount of $\mathrm{H}_{2}$ consumed by drinking hydrogen water influences nitration in in vivo experiments and results in regulatory as well as anti-oxidative effects [11]. These results agree with the present finding that $\mathrm{H}_{2}$ suppressed the nitration of proteins.

Taken together, this study implies that one of the $\mathrm{H}_{2}$ functions, including transcriptional alterations, is caused through reducing $\mathrm{ONOO}^{-}$derived from $\mathrm{NO}$.

Novel pharmacological strategies aimed at selective removal of $\mathrm{ONOO}^{-}$may represent a powerful method for preventive and therapeutic use of $\mathrm{H}_{2}$ for joint diseases. Cartilage has no blood vessels and nutrients are supplied through fluid. Since $\mathrm{H}_{2}$ has a great advantage to rapidly diffuse into tissues even without blood flow [41,42], it may be useful to prevent joint diseases by reducing oxidative stress and by suppressing the decrease in matrix proteins and inhibiting degradation by proteinases.

\section{Conclusions}

This study implies that one of the $\mathrm{H}_{2}$ functions, including transcriptional alterations, is caused through reducing $\mathrm{ONOO}^{-}$derived from NO. Novel pharmacological strategies aimed at selective removal of $\mathrm{ONOO}^{-}$may represent a powerful method for preventive and therapeutic use of $\mathrm{H}_{2}$ for joint diseases. 

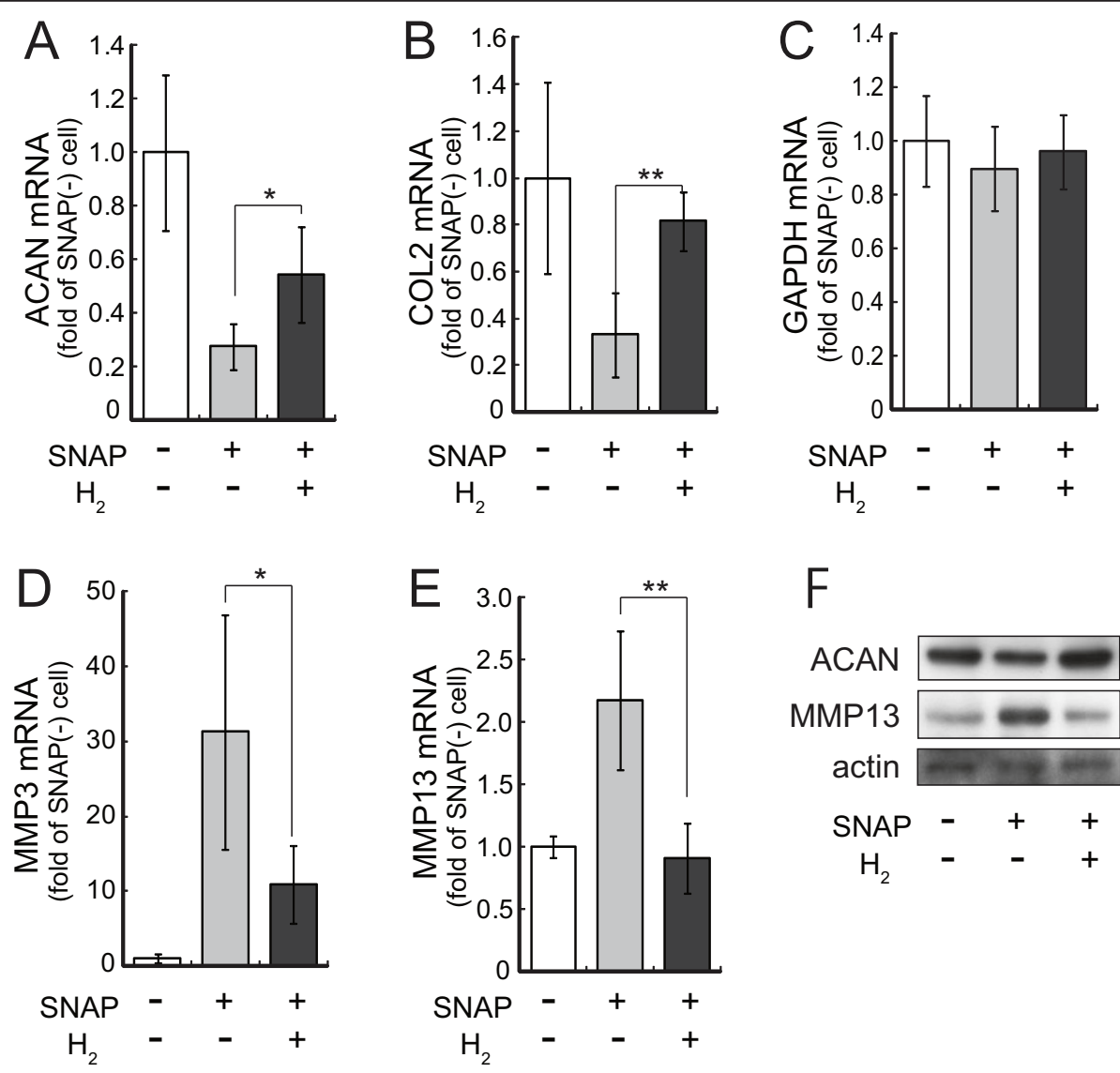

Figure 4 Hydrogen alters mRNA and protein expressions of matrix proteins and matrix-metalloproteases (MMPs). Meniscus fibrocartilage from rats was incubated with $1 \mathrm{mM}$ SNAP in the presence or absence of hydrogen for $4 \mathrm{hr}$ or $20 \mathrm{hr}$ at $37^{\circ} \mathrm{C}$. Total RNA was extracted from 4 hr-incubated cartilage and the expression levels of aggrecan (A), type II collagen (B), GAPDH (C), MMP3 (D) and MMP13 (E) were analyzed by real-time PCR coupled with reverse transcription. Data are the mean \pm SD $(n=4) .{ }^{*} p<0.05 ;{ }^{* *} p<0.01$. (F) Total protein was extracted from 20 hr-incubated cartilage and the expression levels of aggrecan, MMP13 and actin were analyzed by immunoblotting.

\section{Additional material}

Additional file 1: Table S1 - Live, dying, and dead cell numbers of hyaline cartilage.

Additional file 2: Table S2 - Live, dying, and dead cell numbers of fibrocartilages treated with $1 \mathrm{mM}$ SNAP.

Additional file 3: Table S3 - Live, dying, and dead cell numbers of fibrocartilages treated with various concentration of SNAP for 48 hr.

\section{List of abbreviations}

SNAP: S-nitroso-N-acetylpenicillamine; MMP: matrix metalloproteinase; GAPDH: glyceraldehyde 3-phosphate dehydrogenase; OA: osteoarthritis; RA: rheumatoid arthritis.

\section{Acknowledgements}

This work was supported by a grant from the Ministry of Education, Culture, Sports, Science and Technology of Japan and the Ministry of Health, Labour and Welfare.

\section{Author details}

'Department of Biochemistry and Cell Biology, Institute of Development and Aging Sciences, Graduate School of Medicine, Nippon Medical School, 1-396
Kosugi-machi, Nkahara-ku, Kawasaki-city, Kanagawa 211-8533, Japan ${ }^{2}$ Department of Orthopedic Surgery, Nippon Medical School, 1-1-5 Sendagi, Bunkyou-ku, Tokyo, 113-8602, Japan.

\section{Authors' contributions}

SO and ST conceived the experiments. SO and NK designed the actual experiments. TH, TY and NK performed the experiments and data analysis. NK and SO interpreted the data and wrote the paper. All authors have been involved in drafting the manuscript it critically for important intellectual content; and have given final approval of the version to be published.

\section{Competing interests}

The authors declare that they have no competing interests.

Received: 14 February 2011 Accepted: 4 August 2011

Published: 4 August 2011

\section{References}

1. Ohsawa I, Ishikawa M, Takahashi K, Watanabe M, Nishimaki K, Yamagata K, Katsura K, Katayama Y, Asoh S, Ohta S: Hydrogen acts as a therapeutic antioxidant by selectively reducing cytotoxic oxygen radicals. Nat Med 2007, 13:688-694.

2. Fukuda $K$, Asoh S, Ishikawa M, Yamamoto Y, Ohsawa I, Ohta S: Inhalation of hydrogen gas suppresses hepatic injury caused by ischemia/ reperfusion through reducing oxidative stress. Biochem Biophys Res Commun 2007, 361:670-674. 
3. Ohsawa I, Nishimaki K, Yamagata K, Ishikawa M, Ohta S: Consumption of hydrogen water prevents atherosclerosis in apolipoprotein $\mathrm{E}$ knockout mice. Biochem Biophys Res Commun 2008, 377:1195-1198.

4. Kajiya M, Silva MJ, Sato K, Ouhara K, Kawai T: Hydrogen mediates suppression of colon inflammation induced by dextran sodium sulfate. Biochem Biophys Res Commun 2009, 386:11-15.

5. Kajiya M, Sato K, Silva MJ, Ouhara K, Do PM, Shanmugam KT, Kawai T: Hydrogen from intestinal bacteria is protective for Concanavalin Ainduced hepatitis. Biochem Biophys Res Commun 2009, 386:316-321.

6. Itoh T, Fujita Y, Ito M, Masuda A, Ohno K, Ichihara M, Kojima T, Nozawa Y: Molecular hydrogen suppresses FcepsilonRl-mediated signal transduction and prevents degranulation of mast cells. Biochem Biophys Res Commun 2009, 389:651-656.

7. Huang CS, Kawamura T, Toyoda Y, Nakao A: Recent advances in hydrogen research as a therapeutic medical gas. Free Radic Res 2010, 44:971-982.

8. Ohta S: Molecular hydrogen is a novel antioxidant to efficiently reduce oxidative stress with potential for the improvement of mitochondrial diseases. Biochim Biophys Acta 2011.

9. Ohta S: Recent progress toward hydrogen medicine: Potential of molecular hydrogen for preventive and therapeutic applications. Curr Pharm Des 2011

10. Nagata K, Nakashima-Kamimura N, Mikami T, Ohsawa I, Ohta S: Consumption of molecular hydrogen prevents the stress-induced impairments in hippocampus-dependent learning tasks during chronic physical restraint in mice. Neuropsychopharmacology 2009, 34:501-508.

11. Cardinal JS, Zhan J, Wang Y, Sugimoto R, Tsung A, McCurry KR, Billiar TR, Nakao A: Oral hydrogen water prevents chronic allograft nephropathy in rats. Kidney Int 2010, 77:101-109.

12. Fu Y, Ito M, Fujita Y, Ichihara M, Masuda A, Suzuki Y, Maesawa S, Kajita Y, Hirayama M, Ohsawa I, Ohta S, Ohno K: Molecular hydrogen is protective against 6-hydroxydopamine-induced nigrostriatal degeneration in a rat model of Parkinson's disease. Neurosci Lett 2009, 453:81-85.

13. Nakashima-Kamimura N, Mori T, Ohsawa I, Asoh S, Ohta S: Molecular hydrogen alleviates nephrotoxicity induced by an anti-cancer drug cisplatin without compromising anti-tumor activity in mice. Cancer Chemother Pharmacol 2009, 64:753-761.

14. Fujita K, Seike T, Yutsudo N, Ohno M, Yamada H, Yamaguchi H, Sakumi K, Yamakawa Y, Kido MA, Takaki A, Katafuchi T, Tanaka Y, Nakabeppu Y, Noda M: Hydrogen in drinking water reduces dopaminergic neuronal loss in the 1-methyl-4-phenyl-1,2,3,6-tetrahydropyridine mouse model of Parkinson's disease. PLoS One 2009, 4:e7247.

15. Kamimura N, Nishimaki K, Ohsawa I, Ohta S: Molecular hydrogen improves obesity and diabetes by inducing hepatic FGF21 and stimulating energy metabolism in db/db mice. Obesity 2011.

16. Xie K, Yu Y, Pei Y, Hou L, Chen S, Xiong L, Wang G: Protective effects of hydrogen gas on murine polymicrobial sepsis via reducing oxidative stress and HMGB1 release. Shock 2010, 34:90-97.

17. Huang CS, Kawamura T, Lee S, Tochigi N, Shigemura N, Buchholz BM, Kloke JD, Billiar TR, Toyoda Y, Nakao A: Hydrogen inhalation ameliorates ventilator-induced lung injury. Crit Care 2010, 14:R234.

18. Huie RE, Padmaja S: The reaction of no with superoxide. Free Radic Res Commun 1993, 18:195-199.

19. Beckman JS, Beckman TW, Chen J, Marshall PA, Freeman BA: Apparent hydroxyl radical production by peroxynitrite: implications for endothelial injury from nitric oxide and superoxide. Proc Natl Acad Sci USA 1990, 87:1620-1624.

20. Pacher P, Beckman JS, Liaudet L: Nitric oxide and peroxynitrite in health and disease. Physiol Rev 2007, 87:315-424.

21. Klotz LO, Schroeder P, Sies H: Peroxynitrite signaling: receptor tyrosine kinases and activation of stress-responsive pathways. Free Radic Biol Med 2002, 33:737-743.

22. Ozaki D, Sudo K, Asoh S, Yamagata K, Ito H, Ohta S: Transduction of antiapoptotic proteins into chondrocytes in cartilage slice culture. Biochem Biophys Res Commun 2004, 313:522-527.

23. Sudo K, Asoh S, Ohsawa I, Ozaki D, Yamagata K, Ito H, Ohta S: The anti-cell death FNK protein protects cells from death induced by freezing and thawing. Biochem Biophys Res Commun 2005, 330:850-856.

24. Henrotin YE, Bruckner P, Pujol JP: The role of reactive oxygen species in homeostasis and degradation of cartilage. Osteoarthritis Cartilage 2003, 11:747-755.
25. Roach Hl, Aigner T, Soder S, Haag J, Welkerling H: Pathobiology of osteoarthritis: pathomechanisms and potential therapeutic targets. Curr Drug Targets 2007, 8:271-282.

26. Ge Z, Hu Y, Heng BC, Yang Z, Ouyang H, Lee EH, Cao T: Osteoarthritis and therapy. Arthritis Rheum 2006, 55:493-500.

27. Halliwell B: Oxygen radicals, nitric oxide and human inflammatory joint disease. Ann Rheum Dis 1995, 54:505-510.

28. Henrotin Y, Kurz B, Aigner T: Oxygen and reactive oxygen species in cartilage degradation: friends or foes? Osteoarthritis Cartilage 2005, 13:643-654.

29. Muir H: The chondrocyte, architect of cartilage. Biomechanics, structure, function and molecular biology of cartilage matrix macromolecules. Bioessays 1995, 17:1039-1048.

30. Blanco FJ, Ochs RL, Schwarz H, Lotz M: Chondrocyte apoptosis induced by nitric oxide. Am J Pathol 1995, 146:75-85.

31. Del Carlo M, Loeser RF: Nitric oxide-mediated chondrocyte cell death requires the generation of additional reactive oxygen species. Arthritis Rheum 2002, 46:394-403.

32. Clements KM, Burton-Wurster N, Lust G: The spread of cell death from impact damaged cartilage: lack of evidence for the role of nitric oxide and caspases. Osteoarthritis Cartilage 2004, 12:577-585.

33. Whiteman M, Armstrong JS, Cheung NS, Siau JL, Rose P, Schantz JT, Jones DP, Halliwell B: Peroxynitrite mediates calcium-dependent mitochondrial dysfunction and cell death via activation of calpains. FASEB J 2004, 18:1395-1397.

34. Cuzzocrea S, Chatterjee PK, Mazzon E, McDonald MC, Dugo L, Di Paola R, Serraino I, Britti D, Caputi AP, Thiemermann C: Beneficial effects of GW274150, a novel, potent and selective inhibitor of iNOS activity, in a rodent model of collagen-induced arthritis. Eur J Pharmacol 2002, 453:119-129.

35. Szabo C, Virag L, Cuzzocrea S, Scott GS, Hake P, O'Connor MP, Zingarelli B, Salzman A, Kun E: Protection against peroxynitrite-induced fibroblast injury and arthritis development by inhibition of poly(ADP-ribose) synthase. Proc Natl Acad Sci USA 1998, 95:3867-3872.

36. Yonekura Y, Koshiishi I, Yamada K, Mori A, Uchida S, Nakamura T, Utsumi H: Association between the expression of inducible nitric oxide synthase by chondrocytes and its nitric oxide-generating activity in adjuvant arthritis in rats. Nitric Oxide 2003, 8:164-169.

37. Loeser RF, Carlson CS, Del Carlo M, Cole A: Detection of nitrotyrosine in aging and osteoarthritic cartilage: Correlation of oxidative damage with the presence of interleukin-1 beta and with chondrocyte resistance to insulin-like growth factor 1. Arthritis Rheum 2002, 46:2349-2357.

38. Kaur $\mathrm{H}$, Halliwell B: Evidence for nitric oxide-mediated oxidative damage in chronic inflammation. Nitrotyrosine in serum and synovial fluid from rheumatoid patients. FEBS Lett 1994, 350:9-12.

39. Sandhu JK, Robertson S, Birnboim HC, Goldstein R: Distribution of protein nitrotyrosine in synovial tissues of patients with rheumatoid arthritis and osteoarthritis. J Rheumatol 2003, 30:1173-1181.

40. Abramson SB: Osteoarthritis and nitric oxide. Osteoarthritis Cartilage 2008, 16(Suppl 2):S15-20.

41. Hayashida K, Sano M, Ohsawa I, Shinmura K, Tamaki K, Kimura K, Endo J, Katayama T, Kawamura A, Kohsaka S, Makino S, Ohta S, Ogawa S, Fukuda K: Inhalation of hydrogen gas reduces infarct size in the rat model of myocardial ischemia-reperfusion injury. Biochem Biophys Res Commun 2008, 373:30-35.

42. Oharazawa $H$, Igarashi T, Yokota T, Fujii H, Suzuki H, Machide M Takahashi H, Ohta S, Ohsawa I: Protection of the retina by rapid diffusion of hydrogen: administration of hydrogen-loaded eye drops in retinal ischemia-reperfusion injury. Invest Ophthalmol Vis Sci 2010, 51:487-492.

doi:10.1186/2045-9912-1-18

Cite this article as: Hanaoka et al: Molecular hydrogen protects chondrocytes from oxidative stress and indirectly alters gene expressions through reducing peroxynitrite derived from nitric oxide. Medical Gas Research 2011 1:18. 